\title{
New light on old stone: recording and reinventing visual culture
}

\author{
Martin Crampin \\ University of Wales Centre for Advanced Welsh and Celtic Studies \\ National Library of Wales, Aberystwyth, Wales SY23 3HH \\ mcc@aber.ac.uk
}

\begin{abstract}
In this paper the author reflects on his experience of photographing artworks in churches, mainly as part of his role as photographer on the Imaging the Bible in Wales Project (2005-8). The ability to subjectively create new photographic images from original objects is considered and different approaches to photographic recording are evaluated for a variety of effects. An additional perspective on the creation of new images by photographic means is given by the way that medieval visual culture was retained and reused as churches were restored in the second half of the 19th century. This applies not only to 'old stone' but also stained glass, woodcarving and wall painting from the medieval period, which was sometimes crafted into new composite works. In conclusion the author briefly considers the potential for artists to make their own visual interpretations of historical visual culture.
\end{abstract}

Photography. Visual culture. Digital imaging. Bible. Wales. Medieval.

\section{IMAGING THE BIBLE IN WALES}

The Imaging the Bible in Wales Project was funded for three years by the Arts and Humanities Research Council from 2005 until 2008. The purpose of the project was to record and interpret artwork from Wales during the period 1825-1975 that depicted the biblical narrative.

One of the main activities was to photograph a wide selection of artwork from places of worship, which would facilitate the interpretation and form the basis of a corpus on which the publications would be based. The photography was catalogued on the Imaging the Bible in Wales Database, which at the end of the project included over 3,000 images, although it has continued to grow and now includes over 5,000 images.

In an academic world where words are usually given greatest importance, the photographs might seem secondary to the description and interpretation given by the project team and our contributors. But the academic world takes its place within the wider world which is dominated by images, where pictures tell their thousands of words and where visual culture has usurped the dominance of the word, although the creative interplay between the two goes on.

The proper study of visual culture starts with an analysis of the images, initially dispensing with received wisdom, traditional art history, even accepted historical or literary approaches. The range and nature of the material has to be established, as well as its context and those involved in its creation and reception. These other disciplines are useful once we see what questions the images suggest, to propose insights, subtleties and explanations about what the images mean. For the purposes of this project we were also seeking out wider considerations such as the interplay of art and religion, artists' interpretations of the biblical text, and the role of patronage in commissioning religious art.

From the outset of the project we needed to seek out and record artworks, few of which were published in any form. Some of the relevant artwork could be found, as might be expected, in museum and archive collections. Such collections were visited and on some occasions I was permitted to photograph work from museum and private collections. In other instances the repositories supplied their own photography. However, it quickly became apparent that a huge body of work lay largely unrecorded in places of worship. Consisting of sculpture, mural painting and stained glass, this kind of work falls outside of what many regard as fine art, but nonetheless represents a very public form of imagery that is therefore very pervasive in the popular imagination. It is also often an expensive form of art as large church furnishings such as altarpieces and stained glass windows 
could only be commissioned by the wealthy or by the communal giving of a congregation.

\section{PHOTOGRAPHY AND PRESERVATION}

Relevant artwork from the period is being lost at an accelerating rate. Churches are closing every year, and it is believed that chapels may well be closing every week in Wales. Sometimes artworks are preserved in their original context after changes of use, and others find their way into other places of worship, sometimes across parish and denominational boundaries. But some material is destroyed or sold on by architectural antique dealers, often overseas, and the signs are that this will go on at an increasing rate over the next tentwenty years.

Often this is because the artwork is not valued. Stained glass, architectural sculpture and decorative crafts are not appreciated in the same way as what are usually regarded as fine arts, chiefly painting. Furthermore, this kind of artwork was often produced by ecclesiastical furnishing firms, rather than by a single artist, and the romantic perception of the creative artist, working alone, is still very much with us. This sometimes prevents us from appreciating works of art made collaboratively that are nonetheless of great beauty, with the effect that the arts and crafts of 19th and 20th century Wales are at risk.

The photography for the project therefore took on a twin role of providing the images for the analysis of biblical artwork in Wales as well as providing a record of visual art which is in danger of being lost.

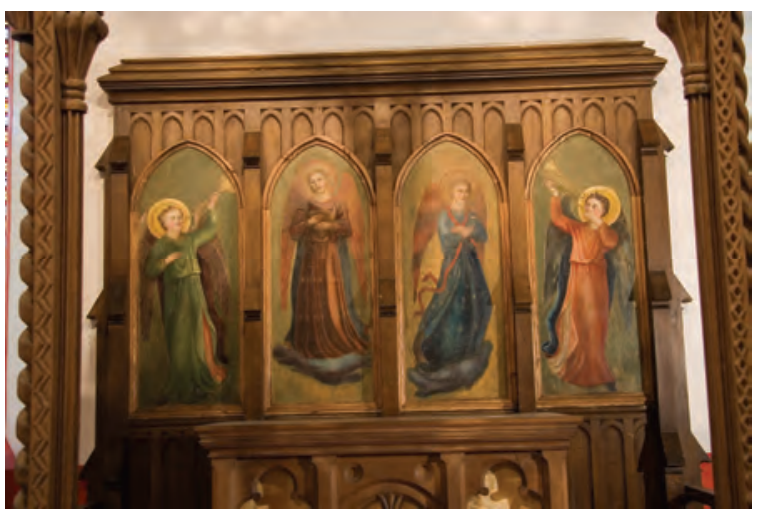

Figure 1: Joshua Stansfield, Four Angels, 1890s, Church of the Holy Trinity, Whitebrook, Monmouthshire

An example of this was encountered at a church in Whitebrook, near Tintern, which had already been closed for some months. It featured some decorative woodcarving and a painted reredos (Figure 1), and as the building has subsequently been sold and converted into a house; these items are unlikely to have survived. The painting and carving were executed by the curate of the church between about 1890 and 1910 . Therefore the work can tell us about the arts and crafts tradition among the clergy, and the occurrence of the trumpeting angels in other media from the period helps us build up set of images derived from a common source.

Museums are clearly not big enough to take many large items like this. A very fine reredos from the 1920s, following designs by Christopher Webb and formerly in the large town church of St James in Cardiff, has now been moved to the Church of St Theodore, Port Talbot after the closure of St James in 2007. The fate of the stained glass and some fine carving from the church is still uncertain. Given this trend the surviving churches will gradually become museums in their own right, and where many centuries of additions and furnishings are already present, in one sense they can be seen as important museums or galleries of art.

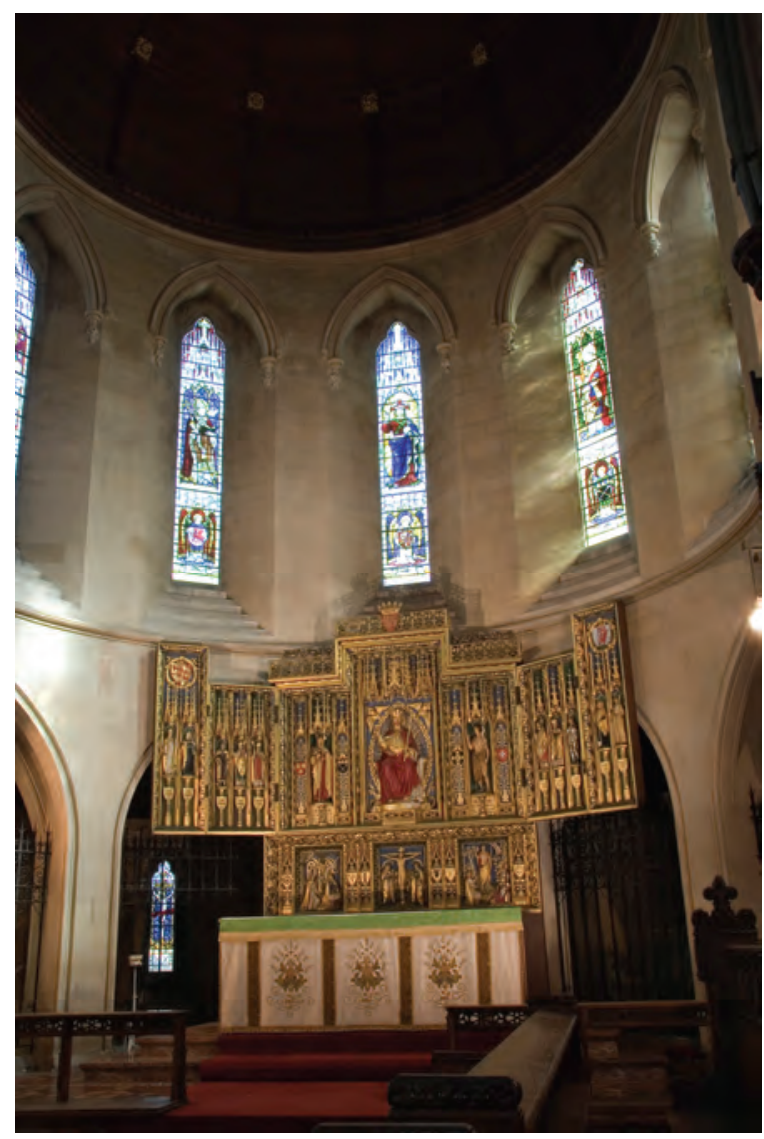

Figure 2: J.B.L. Tolhurst after Christopher Webb, Christ in Majesty with Welsh Saints, about 1927 Church of St James, Cardiff

Where items are being lost from the public domain, either by destruction or sale through the architectural antiques trade, good photographic recording has an important role to play. In a similar spirit, the Royal Commission on the Ancient and 
Historical Monuments of Wales is undertaking a major initiative to document Welsh Nonconformist chapels: buildings which are currently closing or undergoing a change of use at a much faster rate than Anglican and Roman Catholic churches. In the case of the reredos at St James, although it has been preserved in a new location, the photography recording its original context is still valuable; for example the Welsh saints included among the figures echo those above in stained glass (Figure 2).

\section{CREATING A NEW IMAGE}

The photography of this artwork is a kind of recovery, and an interpreted, negotiated process: often much more than a simple opening and closing of the digital shutter. My perspective on this has been informed from practice, which has challenged some of my own assumptions before commencing the work on the project. Furthermore, this recovery of the visual art of the past, as well as its loss, is an ongoing historical process, and one that I believe that we can find analogues for in the past, and I will expand on this below.

Photography is dependent on light, and the nature and quality of that light is perhaps the single most important factor in the photography of the artworks, and one that can radically alter our perception of an object.

The photography of paintings and drawings with a simple two-dimensional surface may be regarded as the least subject to interpretation. Or at least it can be regarded as a straightforward technical skill: you get it right or you get it wrong. But even this is not quite true. There are obviously technical difficulties, such as getting an even light, avoiding glare from lighting or reflections when framed behind glass, and eliminating as much of this as possible is always desirable. But frequently lighting a painting or an object will bring out the colour and texture in a way that is not usually seen. What is often disregarded as a worn old carving or dull Victoriana sometimes surprises. In this way the lighting, and the subsequent photograph, sometimes brings new life to its subject, and creates it anew.

A striking example of this was encountered at the Church of St Mary, Monmouth, where a large dark painting served as the reredos in the sanctuary (Figure 3). It was almost invisible from the nave, but after setting the lights up to photograph it the detail and quality of the work, The Adoration of the Magi by Watney Wilson, was clear. On this occasion a number of local people and parishioners were in the church after an earlier event. The effect of the photographic lights on the painting caused an almost audible gasp, and several of them took photographs with their own digital cameras, as they had not seen the painting look like that before.

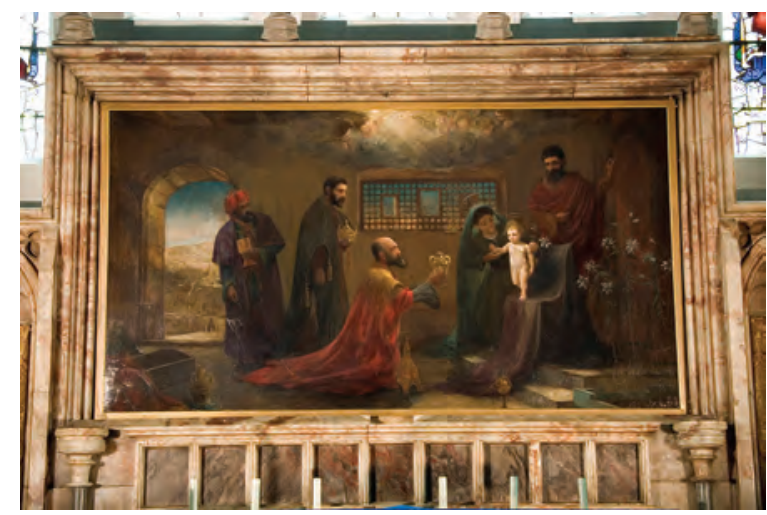

Figure 3: James Watney Wilson, The Adoration of the Magi, 1888, Church of St Mary, Monmouth, Monmouthshire

The area around this painting gives important information about its setting, and its location in a church is clear. But once the image is divorced from the boundaries of its stone surround on the printed page, the viewer would be more likely to imagine that its home was a museum or art gallery (Figure 4).

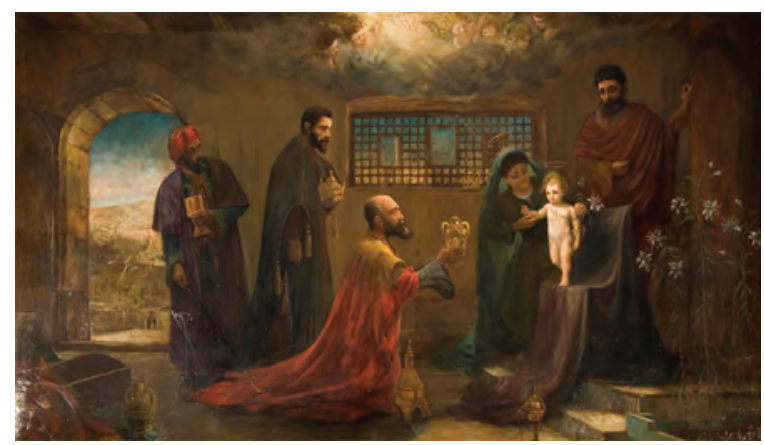

Figure 4: James Watney Wilson, The Adoration of the Magi, 1888, Church of St Mary, Monmouth, Monmouthshire

The colours, brightness and contrast of the photograph are dependent on the available light, which may be altered to create various effects. Stained glass, as a medium that is particularly reliant on light, can also be photographed in different ways depending on the ambient light. With interior light, the nature of the leading and different qualities of the glass can be seen, but the image is often much more dramatic without interior light when the leading is blackened out.

Capturing a dramatic and emotive image can be as desirable as one that might reveal more of the detail and construction of an artefact. Strong lighting gives us a different impression of an artwork, as well as the composition of a twodimensional photograph of a three-dimensional 
object. This has an effect on the interpretation of the artwork. As writers and artists respond to the disseminated images, the most striking images will inevitably receive the most attention. To most viewers over the years the painting illustrated above by Watney Wilson will not have received much attention because it is not usually well lit (and because it is in a church), whereas the detail of a humble font cover at a small church near Harlech (Figures 5 and 6), has the capacity to be made into something more striking.
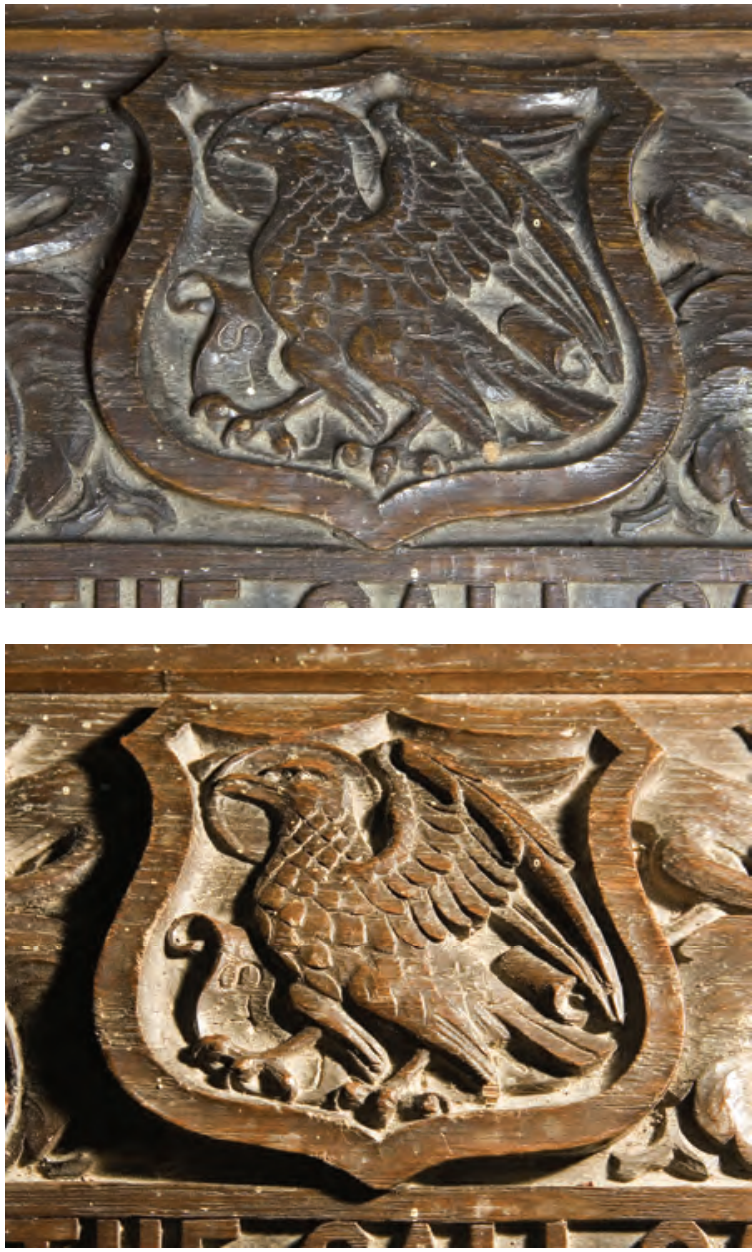

Figures 5 \& 6: Eagle, Symbol of St John the Evangelist, Church of St Peter, Llanbedr, Gwynedd, photographed in natural available light and with additional tungsten lamp

Certain objects present additional challenges for photographic interpretation. The round font by Alan Durst at Llandaff Cathedral (Figures 7 and 8) has a continuous design around the main bowl and a further design around its base. Composing and lighting particular scenes or details creates something new and selective from the hand of the original carver, which is also partial and increasingly devoid of context. These images also have the ability to assume a new independent life of their own. Following an initial encounter with an object via a striking published image, seeing the real object on a later occasion can be altogether more mundane.
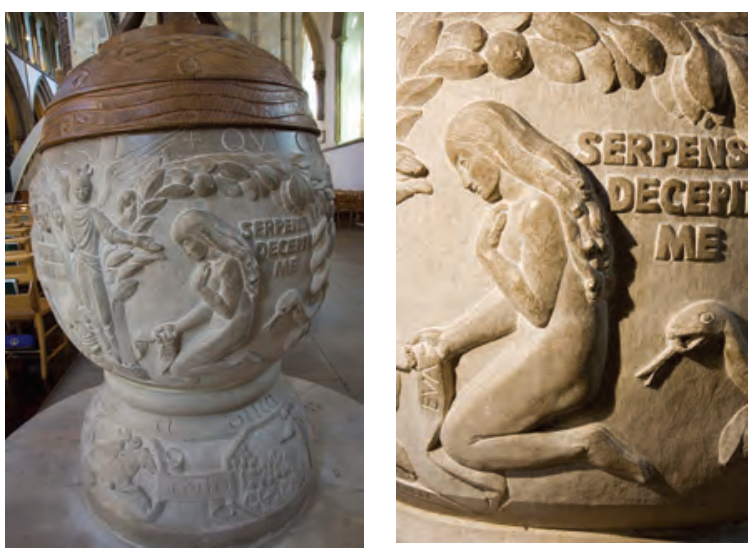

Figures 7 \& 8: Alan Durst, Font, 1952, Llandaff Cathedral, Cardiff, view showing Eve deceived by the serpent, photographed in natural available light and detail with additional tungsten lamp

This has certainly been my experience from a preceding research project, The Visual Culture of Wales. The third volume of the series, Medieval Vision, featured many excellent photographs of medieval visual culture, which were deliberately photographed in a dramatic way intended to achieve the maximum impact both on the printed page and in the electronic version of the volume. In achieving this, a sense of the size and context of the objects was often lost. This sometimes has the effect of making many of the artworks look like museum pieces, and encountering them as a pew end or an architectural corbel can be surprising. Photographing objects in this way certainly elevates the material, drawing attention to what might otherwise simply be curiosities for medievalists.

When photographing visual culture like this ideally all of these considerations need to be borne in mind: recording a 'natural' image, views which are descriptive in terms of context, details, and subjective interpretations adopting certain camera angles and additional lighting. In practice however, time rarely affords the opportunity for such a comprehensive approach to every object encountered, and in many cases only one photograph of an artwork was taken.

However, with the rapid progress of digital photography, there is now more room for postproduction editing of images, as it is now possible to have much more control over the image than we have had in the past. The kind of results that may now be achieved owe a great deal to technological progress in the science of digital photography. It would barely have been possible to get the quality and volume of photography ten years ago without very expensive equipment and more time at each 
site; which means that such a project would have proved prohibitively expensive, and not as wideranging.

The flexibility of the digital images taken is due to the ability to manipulate the camera RAW file after the image has been recorded. Using analogue photography it was usually necessary to bracket exposures and always use additional lighting in dark interiors. When working digitally, adjustments to the exposure, as well as brightness, contrast and colour balance are all possible in RAW conversion software, and there is greater tolerance in low light. Even during the time since the beginning of the project there has been a significant improvement in the processing of camera RAW files.

The opportunities of digital image editing also facilitate the improvement of the photographic image where conditions at the time that the photograph was taken were less than ideal. Usually a better original photograph will always be better than tidying an image up on a computer. However, some problems such as correcting parallax when shooting from below at stained glass windows can be addressed simply in Photoshop, which is more efficient than locating and ascending ladders. But at some sites other objects might obscure the whole view of a mural or window, and photographing it from two different angles and then re-assembling the whole digitally becomes a realistic approach, reconstructing a view of the whole piece which cannot be seen at the actual site.

\section{RECREATING HISTORICAL VISUAL CULTURE}

While photography offers the potential to record and preserve a record of three-dimensional artworks, to a greater or lesser extent creating a new image in a new medium, such ambitions are not original to our age. The recovery and reconstruction of historical artworks has a long history and may be seen in particular at the time of the Gothic Revival during the great period of church restoration and building in the latter half of the 19th century and the early part of the 20th century.

The passage of time had taken its toll on what medieval visual culture had survived in churches after the iconoclasm of the Reformation and the Civil War. As churches were restored and rebuilt, these remains faced a new threat as medieval fabric was refashioned under Victorian restoration. In some instances, usually depending on the architect, medieval features were destroyed, while in other cases they were preserved either in situ or in new contexts. From the 1840s the influence of the Gothic Revival bred a renewed interest in pre-
Reformation artwork and styles, as well as its liturgical practice. Similarly the growing number of antiquarian and historical societies began to draw attention to medieval artwork and architecture. However, this did not always lead to preservation, particularly during the middle years of the 19th century.

So at the same time as artworks were finally being lost, others were being restored and repainted. In a similar way to the recreation of artwork as new photography, carved fragments, pieces of stained glass, and paintings were sometimes rediscovered, and preserved in a new way. Stone fragments were reset into the interior and exterior walls, and sometimes brought together to create a new object. An example of this may be seen in the Trinity Chapel of St David's Cathedral, where the architect W.D. Caröe brought medieval fragments together in the 1920s as a new composite reredos (Figure 9).

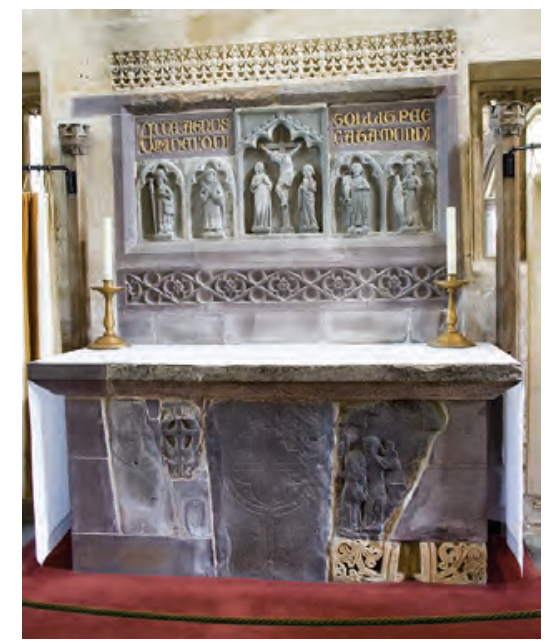

Figure 9: W.D. Caröe, altar and reredos comprising medieval carved fragments, 1920s, St David's Cathedral, Pembrokeshire

In the first half of the 19th century, the restoration of stained glass had a very different kind of meaning to that which is understood today. Firms such as Betton and Evans of Shrewsbury, when commissioned to restore the window at Winchester College Chapel in 1822, found its restoration impossible, taking the glass out and making new painted windows that were inserted in its place. Wales was the recipient of some of this medieval glass, now surplus to requirements, which was inserted into the east window at Worthenbury, near Wrexham, an entirely new creation formed out of old fragments and much new glass.

Another approach to the survival of fragments was to make new composite windows from the parts, not always in a way that made any sense of them. There are several examples of this practice in north-east Wales, such as at Llanrhaedr-yng- 
Nghinmeirch, Hope and Llanfair Dyffryn Clwyd (Figure 10). The latter was restored by J.D. Sedding in 1871-2, and another church restored by the architect in Monmouthshire, also in the 1870s, is a rarer example of the practice in south Wales where medieval glass is more scarce. Perhaps the aesthetic of these composite windows is more palatable to us now than it might have been in Victorian times, in a world yet to witness Cubism, and Abstraction.

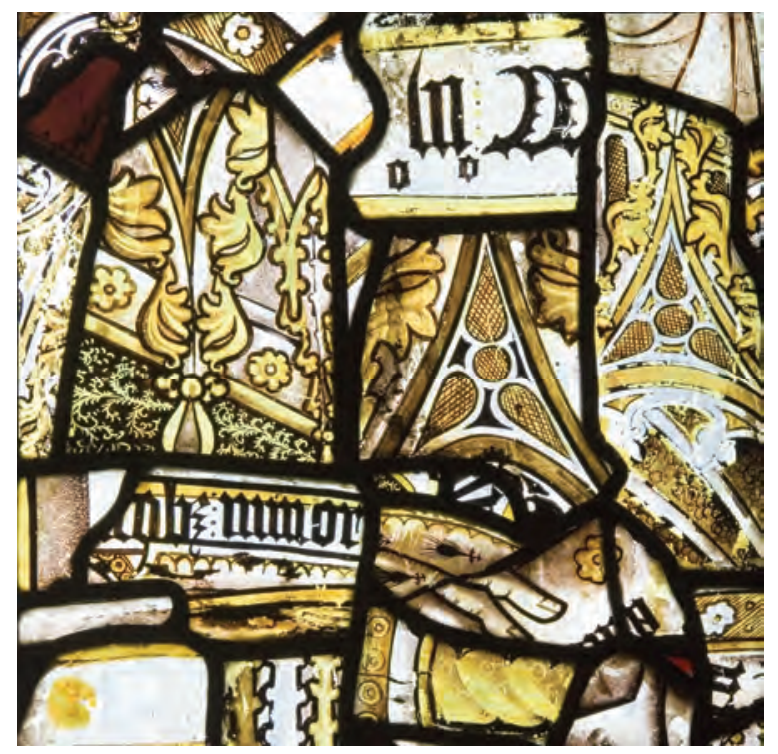

Figure 10: Fragments of medieval stained glass, c. 1503, probably reset c. 1872, Church of St Cynfarch and St Mary, Llanfair Dyffryn Clwyd, Denbighshire

The process of survival, alteration and restoration is most clearly seen at Gresford, also in north-east Wales near Wrexham, which has the most impressive assembly of medieval glass in Wales. Indeed the whole church is full of stained glass, as it once was in medieval times, although the windows in the south, west and much of the north walls are Victorian. There are several assemblies of medieval fragments in the traceries of these windows and in the north wall of the Lady Chapel, although the three east windows appear as more or less complete windows, each containing medieval glass, and restored at different times.

It is not known what state each of the three east windows were in before the middle of the 19th century. Archdeacon Newcombe, vicar of Gresford from 1747-1803, described the glass in the east window of the chancel as:

entirely filled with confused remnants of painted glass ... a figure of a pope, with a triple crown, and one of the Virgin, are perfect; also heads of apostles. (quoted in Fishbourne, 1906, p. 57)

During the restoration of the church in 1867 the glass was completely reset in its current form, but with much new glass added. A Tree of Jesse (Figure 11) can now be seen in the tracery lights above a row of figures, while the main part of the window consists of many figures in the form of a Te Deum. The window was reconstructed by one of the most successful stained glass firms in England, Clayton \& Bell. The firm evidently got on well with the church, because they returned to restore the Lady Chapel east window in 1872, and the Trevor Chapel east window in 1915-6, with the assistance, it is recorded, of further fragments of glass from a box in the crypt.

In the first years of the 20th century, the Vicar of Gresford, Edward Fishbourne, had his own doubts about the likelihood of the window originally representing the Te Deum. He wrote to Clayton and Bell, and Clement Bell, son of the firm's cofounder Alfred Bell, came to visit the window and offer his opinion. He agreed with the Vicar that the words from the Te Deum had been added in 1867 , and also believed that the Tree of Jesse had been a new idea imposed on the remaining medieval fragments. He assisted with the identification of the new and old glass in the window.

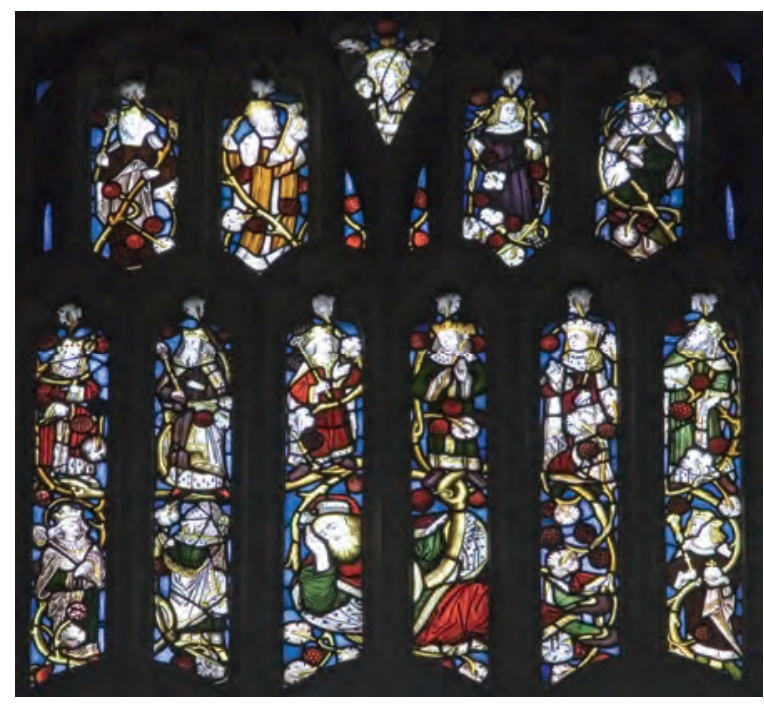

Figure 11: Clayton \& Bell, central part of the Tree of Jesse, 1867 with fragments from 1500, Church of All Saints, Gresford, Wrexham

In his article for Archaeologia Cambrensis, Fishbourne comments:

It is evident, therefore, that the true principles of "restoration" were not properly understood forty years ago, and the window, which originally expressed only the thought of the adoration of all the saints (the church itself being dedicated under the name of All Saints) was altered to express a rather wider idea, not quite so appropriate as the first. (1907, p. 355)

More recently. Mostyn Lewis considered that the Te Deum may in fact have been the original subject 
(Lewis 1970, p. 8), but it cannot be shown how much the remaining pieces of the jigsaw were contrived to create a new picture. But the example demonstrates the practice of restoration and preservation of medieval glass by using historical fragments as the components of what is really a 19th-century creation.

What Fishbourne thought about the 1872 restoration of the window in the Lady Chapel, which includes scenes from the Life of the Virgin we do not know, but one presumes that the 'true principles' of restoration were well observed in 1915-6 by Clayton \& Bell in their reconstruction of the Trevor Chapel east window with scenes from the Life of the John the Baptist and St Anthony. For both of these windows it seems clear that several panels were sufficiently complete for the artists of the firm to fill in missing scenes, or missing parts of the scenes. As Clayton \& Bell were also employed to make five other new windows for the church, which date from around 1868 until 1880, we can see how their new glass, which fits in so well in the restored medieval windows, is so similar to their own Victorian Gothic Revival style.

The question over whether imitating medieval styles was the right thing to do was much debated at the time. Many from the ecclesiological movement and favoured the close copying of medieval styles and colours. Others with a more modern outlook, while valuing the perceived spirit of medieval design, favoured a more contemporary palette and employed an academic drawing style more in keeping with the times. Others proposed dispensing with medieval conventions altogether. Neither was the question limited to stained glass, and we have a good example at Llananno of another close interface with the modern and the medieval in Victorian Wales.

At the Church of St Anno, Llananno, the rood screen effected a rare and lucky survival when the church was restored by the architect David Walker in 1876-7. The church was replaced by a new building on the same site, but the screen was carefully stored before being enlarged to fit the slightly wider span of the nave and re-erected in the new church. The niches on the loft of the screen were empty at the time, as the figures had been destroyed in common with the majority of others from the period. The restoration of the screen in the church was applauded in the antiquarian journal Archaeologia Cambrensis, but concerns were raised about the proposal to insert new figures by the firm of Richard Boulton of Cheltenham in the niches of the loft (1876, pp. 240-1). It was feared that the new figures would look too modern to fit with the medieval work, although the 'completion' of the screen with the new figures surely gives a truer impression of the original than the bare niches would. However, the fact that they were not gaudily painted, which would not have suited their time, or ours, reminds us that the screen remains largely a product of Victorian Wales rather than any kind of close recreation of a medieval rood screen. By way of comparison, the recent attempt to reconstruct and refurnish the Church of St Teilo from Llandeilo Talybont at St Fagans National History Museum features brightly painted figures and painted woodcarving on the rood loft.

The most important medieval survival from the church at Llandeilo Talybont was the series of medieval wall paintings. In this instance, far from being discarded or repainted, as might have been done two hundred years ago, the originals were carefully removed from the walls and conserved, while new paintings based on the surviving fragments have been made on the walls of the rebuilt church.

Wall paintings were also coming to light during the restoration of medieval churches in the 19th century. At Llanbadarn Fawr (Ceredigion) wall paintings were discovered by workmen in 1868 during the restoration of the church by J.P. Seddon, but were plastered over and destroyed by the following year. However at other churches such as at Ruabon and Wrexham, wall paintings were recovered and conserved with an apparent lack of intervention.

But in some cases it would appear that the 'completion' of the design was regarded as necessary, as demonstrated by the restored panels at Llanelian-yn-Rhos (Figure 12). While there is no reason to assume that the original composition was any different, there is a good deal of room to speculate how much of the crudity of the overpainting is medieval or Victorian, and difficult to ascertain whether we should regard it as largely a creation of the 15th or the 19th century.

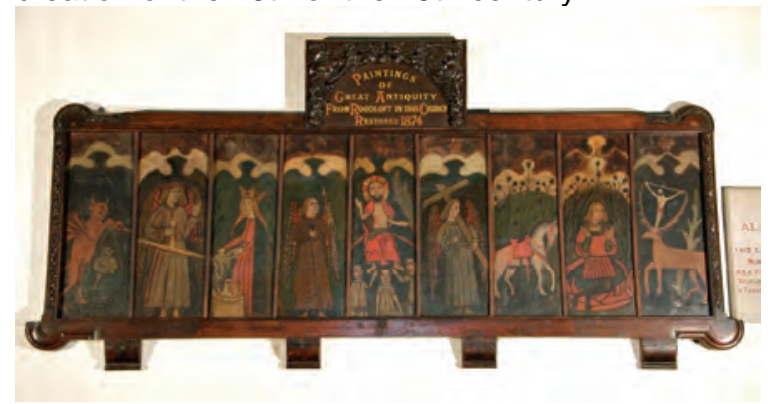

Figure 12: Scenes from the medieval roodloft, 15th century, restored 1874, Church of St Elian, Llanelian-yn-Rhos, Denbighshire

If it is overpainting which simply follows the design of the medieval original, then we are not so far away from the work of Clayton and Bell and others of their time who carefully observed and copied 
medieval originals in new glass. It may be that the scenes were barely visible. At the same church further panelling over the sanctuary has traces of medieval painting, little of which can now be deciphered. Perhaps the painter of the restored scenes carefully tried to bring to light what was already on the surface of the wood, by following the style and pigment of the original, in an attempt to make what was almost lost visible again.

\section{NEW INTERPRETATIONS}

At a time when high quality colour photography was not possible, perhaps the purpose of the artist at Llanelian-yn-Rhos may not have been far from my own attempts to make the visual culture of the past visible for future generations. The photography for the Imaging the Bible in Wales Project was mainly intended to be a literal interpretation of its original condition, or at least that in which I found it. Even in the space of a hundred years or less, carving was subsequently gilded and objects moved or adapted.

The visual culture of the medieval past has been a source for artists and architects in a variety of ways. As we have seen, as well as those who physically manipulated the material remains into new objects, artists made new drawings of what they found, or sometimes adopted the coloration, style and composition in their own new works across a range of media. In many cases this was as part of an antiquarian, and then an increasingly archaeological, spirit of recording, and then of imitating medieval art.

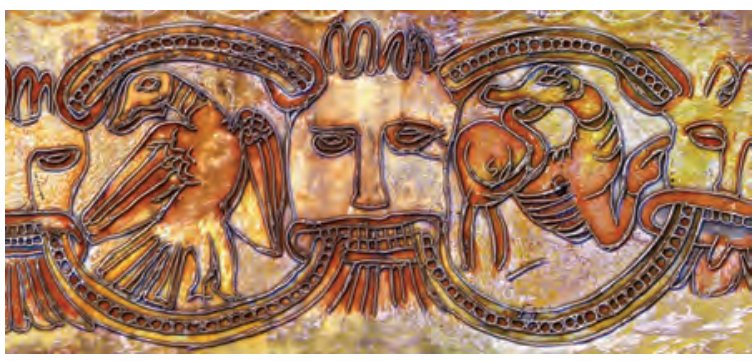

Figure 13: Martin Crampin, Brecon Font, 2005, digital image, detail

I have adopted a particular blend of this approach in my own practice as an artist. In one sense it attempts to make an entirely new image, but as it is closely dependent on medieval stone and woodcarving it is also partly recording and a virtual restoration, interpreted in colour and in two dimensions. Examples such as Brecon Font (2005) (Figure 13) show how the carvings around the bowl of the font may be photographed, montaged, redrawn and digitally crafted into a view of the font that cannot be seen at the cathedral where the font may be found. This example employs a tentative use of colour unlike my interpretations of the panels of the screen at Llananno, which use a broader palette unlike both the plain wood now extant or the kind of coloration likely at the time of their original installation.'

By adding these examples to those above, I have sought to express a fuller range of potential for the visual interpretation of historical visual culture. This is both a creative and subjective process and questions the notion of 'faithfully recording' a threedimensional and context-bound visual culture. Such visual representation does, and should, operate at different levels for particular purposes and needs to be appreciated and accommodated when recording and publishing this kind of material. This can then support a flexible and informed interpretation in parallel with a creative manipulation in the visual vocabulary of the present, making it visible for the future.

\section{REFERENCES}

[Anon] (1876) Archaeological Notes and Queries, Archaeologia Cambrensis, fourth series, 17, pp. 239-242.

Crampin, M. \& Morgan-Guy, J. (2008-10) Imaging the Bible in Wales Database.

http://imagingthebible.llgc.org.uk (25 March 2010).

Crampin, M. \& Morgan-Guy, J. (2010) Imaging the Bible in Wales (DVD-ROM). Sheffield Phoenix Press, Sheffield.

Fishbourne, E. (1906) The Parish Church of All Saints', Gresford. Phillipson \& Golder. Chester.

Fishbourne, E. (1907) Notes on the East Window of the Church of All Saints, Gresford. Archaeologia Cambrensis, pp. 352-7.

Lewis, M. (1970) Stained Glass in North Wales up to 1850. John Sherratt \& Son Ltd, Altrincham.

Lord, P. (2003) The Visual Culture of Wales: Medieval Vision. University of Wales Press, Cardiff.

Lord, P. (2004) The Visual Culture of Wales: Medieval Vision (CD-ROM). University of Wales Press, Cardiff.

Morgan-Guy, J. \& O'Kane, M. (2010) Biblical Art from Wales. Sheffield Phoenix Press, Sheffield.

\footnotetext{
i For further examples of work see http://www.martincrampin.co.uk/images.htm (25 March 2010).
} 